\title{
Facile One-pot Synthesis of A Novel Propargyl-Azulene Hybrid Derivative: Cycloaddition Reaction and Some Spectroscopic Properties
}

\section{Musa ERDOĞAN ${ }^{1 *}$}

\begin{abstract}
Guaiazulene, 1,4-dimethyl-7-isopropylazulene, is one of the non-benzenoid aromatic compounds consisting of fused of the seven- and the five-membered ring. Guaiazulene is an important natural product and having great potential due to its unique optical and electronic properties. In this study, a method for propargyl insertion into the C-4 methyl group of the guaiazulene is developed. A one-pot reaction of the guaiazulene, LDA, and propargyl bromide in THF affords the corresponding a new propargyl-azulene hybrid derivative. Additionally, Diels-Alder cycloaddition reaction between the propargyl-GA and tetraphenylcyclopentadienone was performed, and the cycloadduct was obtained with excellent yield. The structures of new compounds were elucidated on the basis of extensive spectroscopic (IR, NMR, and UV-vis) data analysis. This approach may be potentially useful for the development of the new azulene derivatives.
\end{abstract}

Keywords: Azulene, guaiazulene, propargylation, alkynylation, one-pot synthesis, Diels-Alder, cycloaddition

\footnotetext{
${ }^{1}$ Musa ERDOĞAN (Orcid ID: 0000-0001-3097-2862), Kafkas Üniversitesi, Mühendislik Mimarlık Fakültesi, Gıda Mühendisliği Bölümü, Kars, Türkiye.

*Sorumlu Yazar/Corresponding Author: Musa ERDOĞAN, musaerdogan0@gmail.com 


\section{INTRODUCTION}

Azulene (1) is a non-alternant aromatic hydrocarbon that has fascinated chemists for many years due to its excellent blue color and high dipole moment (Cowper et al., 2016; Narita et al., 2018). Azulene skeleton is one of the bicyclic aromatic systems containing $10 \pi$-electron (Kiriazis et al., 2017) (Figure 1). The azulene (1) one of the isomer of colorless naphthalene and displays a blue color that has fascinated people since medieval times (Amir et al. 2011; Woodward et al., 2016). In general, naturally occurring derivatives can be obtained from plant sources (Gordon, 1952). The most typical features of azulene derivatives are the ability to have redox processes easily. It has also a polar character due to the contributions of charged aromatic scaffold structures such as cyclopentadienyl anion and tropylium cation (Aumüller and Yli-Kauhaluoma 2009). The fused two-ring system contributes to the dipolar nature of the molecule with a high, $1.08 \mathrm{D}$ dipole moment and increased reactivity. Five-membered cyclopentadienyl unit of the azulene carries a partial negative charge, so electrophilic aromatic substitution reactions ( $\mathrm{S}_{\mathrm{E}} \mathrm{Ar}$ ) occur at the $\mathrm{C} 1$ and C3 positions of this unit (Székely et al., 2017). Therefore, substituted azulene reported in the literature relates to the positions, which are the most reactive in $\mathrm{S}_{\mathrm{E}} \mathrm{Ar}$ reactions.

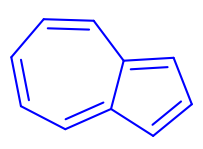

Azulene (1)

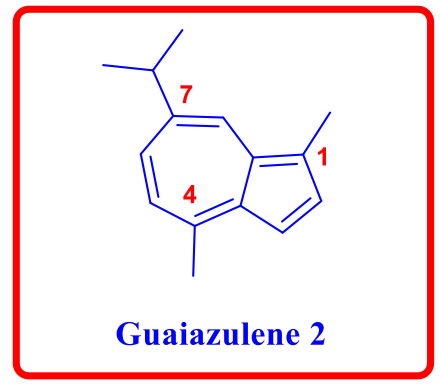

Guaiazulene 2

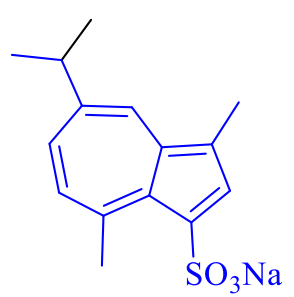

Sodium guaiazulene sulfonate $\mathbf{3}$

Figure 1. Structures of azulene (1), guiazulene 2 and sodium guiazulene sulfonate 3 .

With their unique chemical and electronic properties, the substituted azulenes have diverse applications in medicinal chemistry (as antiulcer (Yanagisawa et al., 1988), antidiabetic (Imamura et al., 2012), anticancer (Asato et al., 1993), antiarrhythmic (Tanaka and Shigenobu, 2001) and anti-erectiledysfunction (Shoji et al., 2020) agents, and as TXA2 receptor antagonists (Tomiyama et al., 1993)), in photosensitizers (Ghasimi et al., 2016), multistate switches (Vlasceanu et al., 2016), as metal-organic frameworks for hydrogen storage (Barman et al., 2010), chromophores (Wang et al., 1999; Zadeh et al., 2015).

Guaiazulene (GA) $\mathbf{2}$ is a natural derivative of the azulene (1) and can be extracted from plants. It is found in nature as a component of the pigments of mushrooms, guaiac wood oil, and some marine invertebrates, and these natural resources currently serve as commercial sources. The GA 2 is an FDA approved cosmetic color additive and has potential applications as an anti-inflammatory, pain reliever, antioxidant, antiviral, and anti-ulcer drug. Due to its rose-like scent, it is used as a fragrance in some formulations. Because of these multiple uses, the discovery of simple access to guaiazulen derivatives would be very useful (Zhao et al., 2013). The GA 2 is the main active ingredient of the plant 'Matricaria chamomilla L.', and displays alluring pharmacological properties, including antipepsin, antiinflammatory, antianaphylaxis and promoting mucosa's metabolism (Zhang et al., 2011; Cao et al., 2016). Sodium guaiazulene sulfonate 3, a hydrophilic derivative of GA 2 with its excellent antiinflammatory effect, is the main component of Compound Glutamine Granules which used in gastric ulcer treatment (Seo et al., 1996; Chen et al., 2012). Among the known natural pigments, the GA 2 has recently gained popularity due to its interesting physical and electronic properties. As a non-toxic natural 
product found in Guajacum Officinale and Matricaria chamomilla oils and lively blue mushroom Lactarius indigo, the GA 2 is approved by the FDA as a cosmetic color additive. GA core exhibits a relatively large permanent dipole moment because it contains a fused electron-rich cyclopentadiene and electron-poor heptathrine skeleton, which causes aromatic delocalization energy to be 5 times lower than that of benzene (Zhao et al., 2013; Ghazvini et al., 2015) (Figure 2).

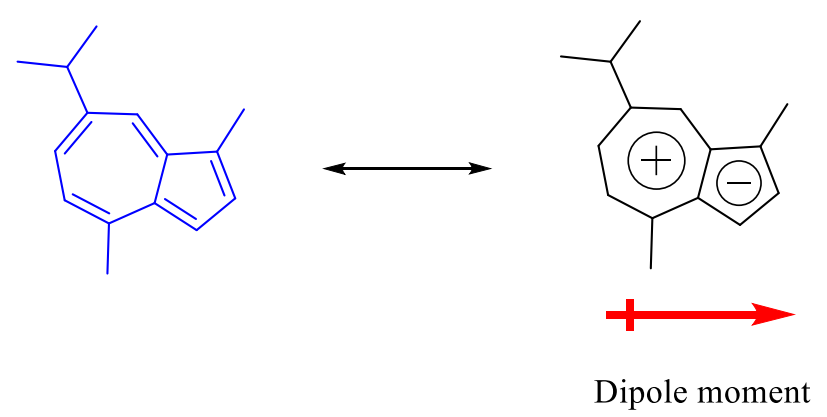

Figure 2. Resonance structures of the guiazulene 2.

The GA core has low transition energy to the S1 state and an unusually large S1-S2 gap, where S1 and S2 refer to the first and second electronically excited states, respectively. As a result of the high electron density in the C-3 position, the GA 2 can easily participate in the $S_{E} A r$. In fact, the treatment of GA 2 with strong acids leads to protonation at the C-3 position and the formation of a resonancestabilized $6 \pi$-electron tropilium cation. Conjugated systems, resulting from hybridization of the GA nucleus with different conjugated units, show significant optical, electrochemical, and electrochromic properties (Zadeh et al., 2015). These systems have diverse applications such as modular building blocks for the construction of conducting polymers, as cathode modification layers in bulk-heterojunction solar cells, and in electrochromic and nonlinear optical materials (Takekuma et al., 2012; Ghazvini et al., 2015). Despite all this, these fascinating and electronic approaches often suffer from excessively long, low efficiency, or general lack. Access to most of azulens' replacement templates is still difficult (Crombie et al., 2004; Carret et al., 2005). Therefore, the development of efficient synthetic methods of these compounds from the easily available starting materials is in constant demand. In this context, it is important to hybridize the GA with an important functional group due to the preparation of azulene derivatives (Park et al., 2014).

There is a limited number of synthesis related to derivatives from 4 positions of the GA in the literature (Kurokawa, 1983; Razus et al., 2008; Aumüller et al., 2011; Zhao et al., 2013; Cao et al., 2016; Woodward et al., 2016). There is also only one study in the literature that is about directly the propargylation from the 3-position of GA core (Székely et al., 2017) [8]. Herein, we focus on the placed of propargyl into the 4-position on the seven-membered ring of the GA scaffold. This approach offered the possibility of synthesizing a new propargyl-azulene hybrid derivative. We also examined the DielsAlder cycloaddition reaction between the obtained propargyl-GA 4 and tetraphenylcyclopentadienone 5.

\section{MATERIALS AND METHODS}

\section{Materials}

The reaction was carried out under nitrogen atm. and monitored by TLC and/or ${ }^{1} \mathrm{H}-\mathrm{NMR}$ spectroscopy. THF, used as a solvent, was dried and distilled before use. Column chromatography was performed on silica gel (60 mesh, Merck) or on neutral alumina. TLC was carried out on silica gel 60 HF254 aluminum plates (Fluka). The one and two dimensional ${ }^{1} \mathrm{H}$ spectra were recorded on a Varian- 
400 or a Bruker- 400 spectrometer in $\mathrm{CDCl}_{3}$ using tetramethylsilane as the internal reference. All spectra were recorded at $25^{\circ} \mathrm{C}$ and coupling constants ( $J$ values) are given in Hz. Chemical shifts are given in parts per million (ppm). Abbreviations used to define the multiplicities are as follows: $s=$ singlet; $d=$ doublet; $\mathrm{dd}=$ doublet of doublets; $\mathrm{td}=$ triplet of doublets. IR spectra were recorded on an Perkin Elmer FT-IR spectrometer. Absorption spectrometry was performed using a Perkin Elmer Lambda 35 spectrophotometer. Absorbance spectroscopy measurement was kept in $\mathrm{CH}_{2} \mathrm{Cl}_{2}(5 \mu \mathrm{M})$.

\section{Experimental procedure}

Synthesis of the propargyl-GA 4: Under nitrogen atm., a solution of $n$-BuLi in hexane (2.5 M, $2.52 \mathrm{~mL}, 6.30 \mathrm{mmol})$ was added to a solution of dry diisopropylamine $(1.24 \mathrm{~mL}, 8.82 \mathrm{mmol})$ in dry THF $(10 \mathrm{~mL})$ cooled at $-78{ }^{\circ} \mathrm{C}$. After $40 \mathrm{~min}$, a solution of guaiazulene $2(0.50 \mathrm{~g}, 1.31 \mathrm{mmol})$ in dry THF (15 ml) was added and the mixture was maintained at the same temperature for $30 \mathrm{~min}$. The solution is allowed to warm to $-10{ }^{\circ} \mathrm{C}$. During this time the color changes from blue to brown-yellow. Then, the solution is cooled again to $-78{ }^{\circ} \mathrm{C}$ and the propargyl bromide $(0.30 \mathrm{~mL}, 2.77 \mathrm{mmol}, 80 \mathrm{wt} . \%$ in toluene $)$ is added dropwise. The solution is stirred for $30 \mathrm{~min}$ at $-78{ }^{\circ} \mathrm{C}$ and then allowed to warm to rt slowly. The resulting mixture was stirred at the same temperature for $12 \mathrm{~h}$. Meanwhile, a color change from brown-yellow to black-blue is observed. The final mixture was diluted with water $(50 \mathrm{~mL})$ and extracted with EtOAc $(3 \times 50 \mathrm{~mL})$. Combined EtOAc extracts were dried over $\mathrm{Na}_{2} \mathrm{SO}_{4}$, and concentrated in vacuo. The crude product was purified by column chromatography on silica gel ( $25 \% \mathrm{EtOAc} / n$-hexane). The obtained solid was recrystallized from $\mathrm{CH}_{2} \mathrm{Cl}_{2} / n$-hexane (9:1) to give black-blue crystals the propargylGA 4 (yield $580 \mathrm{mg}, 97 \%$ ). 4-(But-3-yn-1-yl)-7-isopropyl-1-methylazulene (4): Mp. $134{ }^{\circ} \mathrm{C},{ }^{1} \mathrm{H}$ NMR $\left(400 \mathrm{MHz}, \mathrm{CDCl}_{3}\right): \delta=8.20(\mathrm{~d}, J=1.8 \mathrm{~Hz}, 1 \mathrm{H}), 7.66(\mathrm{~d}, J=3.7 \mathrm{~Hz}, 1 \mathrm{H}), 7.44(\mathrm{dd}, J=10.7,1.8 \mathrm{~Hz}$, 1H), $7.29(\mathrm{~d}, J=3.7 \mathrm{~Hz}, 1 \mathrm{H}), 7.05(\mathrm{~d}, J=10.7 \mathrm{~Hz}, 1 \mathrm{H}), 3.40$ (t, $J=7.5 \mathrm{~Hz}, 2 \mathrm{H}), 3.09$ (sept, $J=6.9 \mathrm{~Hz}$, $1 \mathrm{H}), 2.70(\mathrm{td}, J=7.5,2.5 \mathrm{~Hz}, 2 \mathrm{H}), 2.68(\mathrm{~s}, 3 \mathrm{H}), 2.04(\mathrm{t}, J=2.5 \mathrm{~Hz}, 1 \mathrm{H}), 1.37(\mathrm{~d}, J=6.9 \mathrm{~Hz}, 6 \mathrm{H}) . \mathrm{IR}$ $\left(\mathrm{cm}^{-1}\right): 3289,2962,2928,2871,2117,1695,1602,1432,1384,1362,1156,1067,1052$.

Synthesis of the compound 6: Tetraphenylcyclopentadienone 5 (0.976 g, $2.54 \mathrm{mmol})$ was added to a solution of the propargyl-GA $4(0.500 \mathrm{~g}, 2.12 \mathrm{mmol})$ in $o$-xylene $(30 \mathrm{~mL})$ under $\mathrm{N}_{2}$ atm. The reaction mixture was heated for $12 \mathrm{~h}$ at $160{ }^{\circ} \mathrm{C}$. The resulting reaction mixture was poured into $\mathrm{MeOH}$ and the precipitate filtered off. The cycloadduct 6 was obtained by repeated precipitation from EtOH until the red color of the tetraphenylcyclopentadienone $\mathbf{5}$ had disappeared. The residue was purified via column chromatography on silica gel $(100 \mathrm{~g})$ by eluting with $5 \% \mathrm{EtOAc} / n$-hexane to give the cycloadduct 6 (1.22 g, 97\%). 4-(2-(3',6'-Diphenyl-[1,1':2',1'-terphenyl]-4'-yl)ethyl)-7-isopropyl-1-methylazulene (6): Mp. $139-141^{\circ} \mathrm{C} .{ }^{1} \mathrm{H}$ NMR (400 MHz, $\left.\mathrm{CDCl}_{3}\right): \delta=8.15(\mathrm{~d}, J=1.8 \mathrm{~Hz}, 1 \mathrm{H}), 7.52-7.50(\mathrm{~m}, 2 \mathrm{H}), 7.34$ $(\mathrm{dd}, J=1.8,10.6 \mathrm{~Hz}, 1 \mathrm{H}), 7.27-7.15(\mathrm{~m}, 9 \mathrm{H}), 6.94-6.81(\mathrm{~m}, 11 \mathrm{H}), 6.77(\mathrm{~d}, J=3.7 \mathrm{~Hz}, 1 \mathrm{H}), 6.73(\mathrm{~d}, J=$ $10.6 \mathrm{~Hz}, 1 \mathrm{H}), 3.31-3.27$ (m, 2H), 3.11-3.04 (m, 3H), 2.64 (s, 3H), 1.35 (d, $J=7.0 \mathrm{~Hz}, 6 \mathrm{H}) .{ }^{13} \mathrm{C} \mathrm{NMR}$ $\left(100 \mathrm{MHz}, \mathrm{CDCl}_{3}\right): \delta=148.43,142.21,142.06,141.08,140.83,140.65,140.30,140.27,139.92,139,43$, $138.38,137.08,136.62,136.11,135.49,133.38,131.83,131.49,130.88,130.67,130.19,127.93,127.80$, $127.09,126.77,126.52$, 126.42, 125.71, 125.49, 125.36, 124.78, 112.53, 40.67, 38.47, 36.43, 24.99, 13.13. IR ( $\left.\mathrm{cm}^{-1}\right): 3054,3023,2958,2928,2866,1710,1600,1575,1555,1526,1495,1440,1387,1364$, $1321,1263,1206,1178,1154,1072,1026,912,887,807$. 


\section{RESULTS AND DISCUSSION}

\section{Synthesis}

Starting from the GA 2, more that one methyl group can be involved by the nucleophilic addition. Our approach was to extend the guaiazulene carbon framework through nucleophilic addition of the resonance-stabilized anion $2-$ to propargyl bromide, yielding the propargyl-GA 4. It is well known that, due to the hyperconjugation of methyl at the 4-positions of a GA 2, the C $\alpha$ protons of the alkyl groups can be removed using a strong base such as LDA (Balduzzi et al., 2004). Typically, the resulting azulene carbanions are quite stable due to the presence of an aromatic cyclopentadienyl anionic moiety in their resonance forms. In the literature, the carbanion $2^{-}$has a limited number of nucleophilic addition reactions with electrophilic centers (Kurokawa, 1983; Razus et al., 2008; Balduzzi et al., 2004; Aumüller et al., 2011; Woodward et al., 2016). The GA 2, which was commercially available, became the key structure that allowed us to prepare propargyl-GA 4.

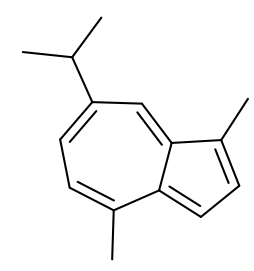

2
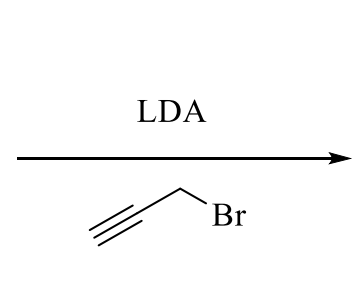

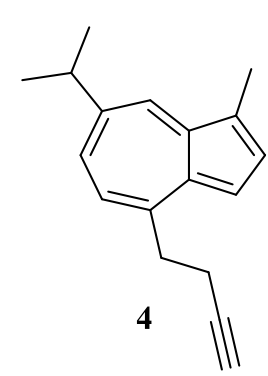

Figure 1. One-pot reaction for the synthesis of the compound 4 via nucleophilic addition.

In this study, we report the one-pot synthesis of the propargyl-GA 4, and its activation step based on Diels-Alder cycloaddition. Firstly, the compound $\mathbf{4}$ was synthesized by the nucleophilic addition reaction of the propargyl bromide with GA carbanion 2-, which was obtained in situ as a result of the reaction between the acidic $\mathrm{H}$-atom of the methyl group existing in the 4-position of the guaiazulen ring and LDA in THF solution (Figure 1-2), in excellent yield 97\%. Then, the compound 6 was obtained by the Diels-Alder cycloaddition between the propargyl-GA 4 and tetraphenylcyclopentadienone $\mathbf{5}$ in excellent yield $97 \%$ (Figure 3).

\section{NMR and FT-IR analysis}

The ${ }^{1} \mathrm{H}-\mathrm{NMR}$ spectrum of compound 4 consists of sets of signals appearing in aromatic and aliphatic regions (Figure 4). In comparison with Spectra 1 in Figure 3, Spectra 2 in Figure 4 was observed that the signal of the C-4 methyl group of the guaiazulene scaffold was disappeared. In addition, it was observed that three new signals were formed in the aliphatic region, which is 3.40, 2.70, and $2.04 \mathrm{ppm}$ in Figure 4. The aromatic Ha protons are split into triplet only by the coupling with $\mathrm{Hb}$ protons $\delta=3.40$ (t, $J=7.5 \mathrm{~Hz}, 2 \mathrm{H}_{\mathrm{a}}$ ). $\mathrm{Hb}$ protons resonate as a triplet of doublets at $2.70 \mathrm{ppm}$ from the coupling firstly with $\mathrm{Ha}$ and then with Hc protons, two different coupling constants of $(J=7.5,2.5 \mathrm{~Hz})$. In addition, the acetylenic Hc proton, one of the most specific peaks, resonates as a triplet at $2.04 \mathrm{ppm}(\mathrm{t}, J=2.5 \mathrm{~Hz}$, $1 \mathrm{H}_{\mathrm{c}}$ ) due to only by the coupling with $\mathrm{Hb}$ protons. 


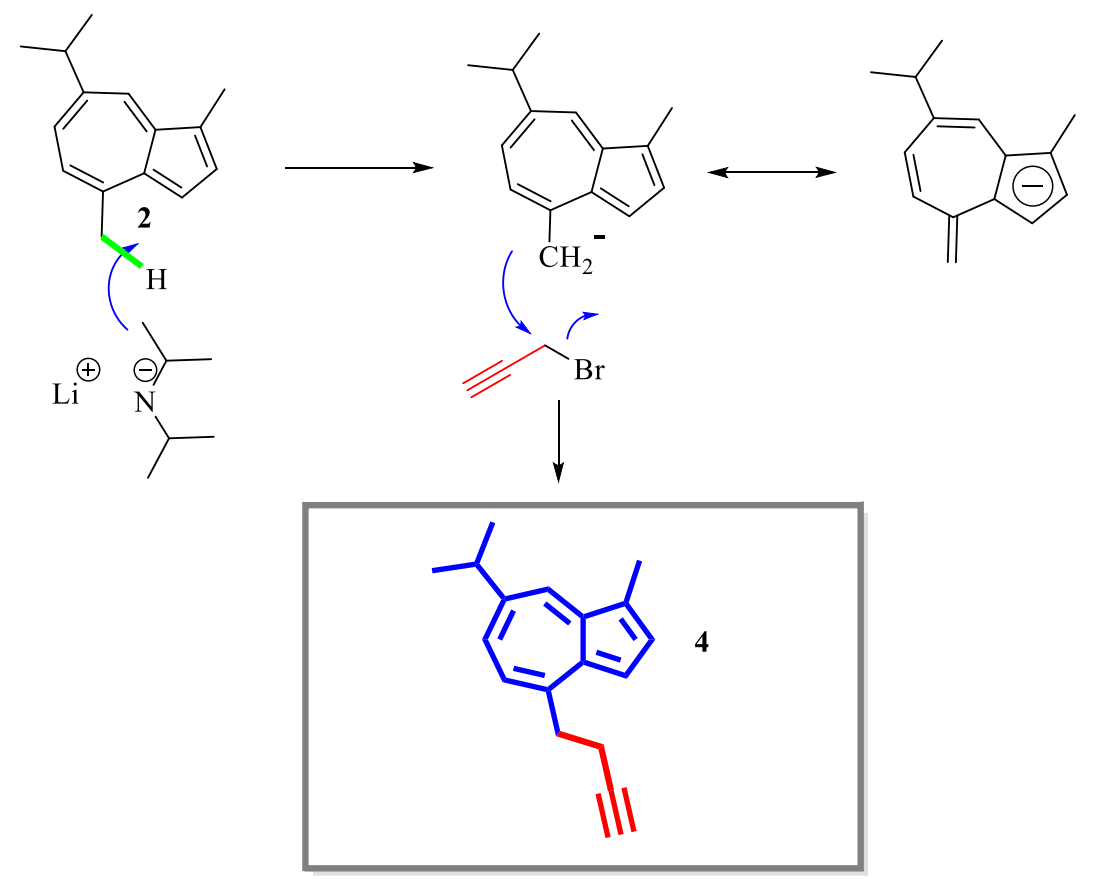

Figure 2. Synthesis mechanism for the formation of the compound 4.
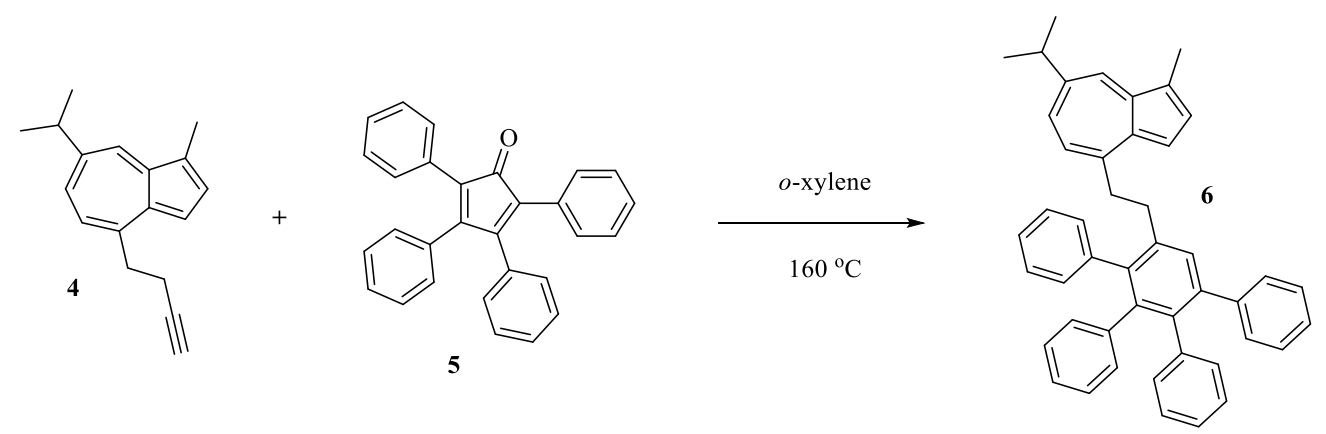

Figure 3. Synthesis of cycloadduct 6

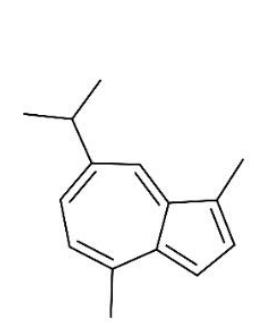

2

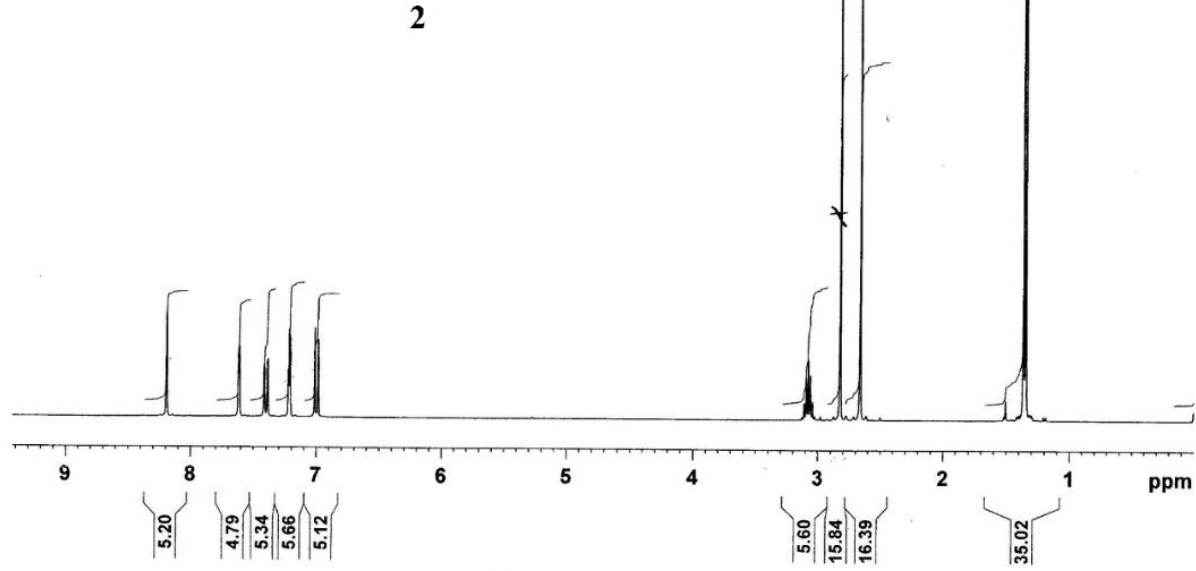

Figure 3. ${ }^{1} \mathrm{H}-\mathrm{NMR}\left(400 \mathrm{MHz}, \mathrm{CDCl}_{3}\right)$ spectrum of the compound 2 (Spectra 1$)$. 


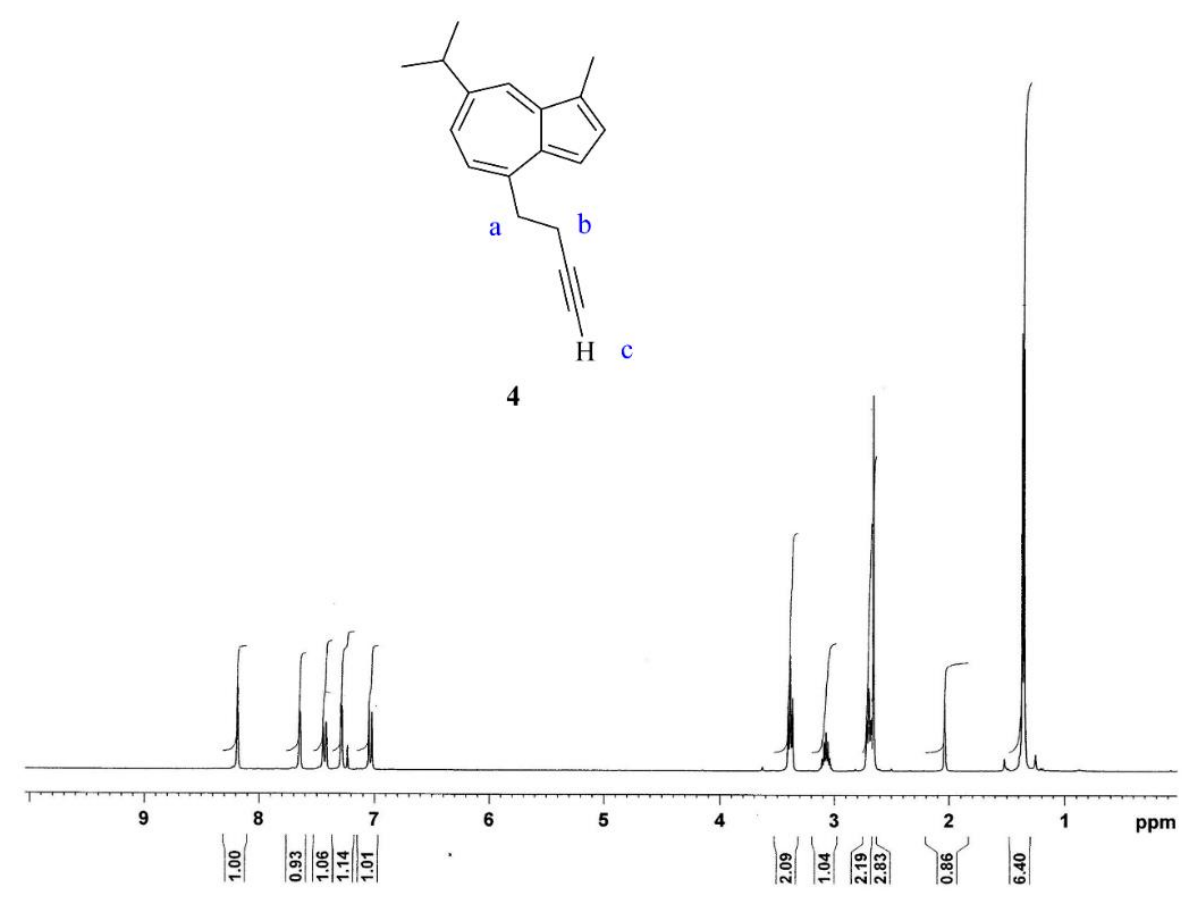

Figure 4. ${ }^{1} \mathrm{H}-\mathrm{NMR}\left(400 \mathrm{MHz}, \mathrm{CDCl}_{3}\right.$ ) spectrum of the compound 4 (Spectra 2).

In similar to, the ${ }^{1} \mathrm{H}-\mathrm{NMR}$ and ${ }^{13} \mathrm{C}-\mathrm{NMR}$ spectrum of cycloadduct 6 consists of sets of signals appearing in aromatic and aliphatic regions (Figure 5-6). In comparison with the Spectra 2 (Figure 4), in the Spectra 3 (Figure 5) was observed that the signal of the propargyl functional group of the propargyl-GA 4 was disappeared. Additionally, the NMR data were in very good agreement with the structure of the cycloadduct 6.

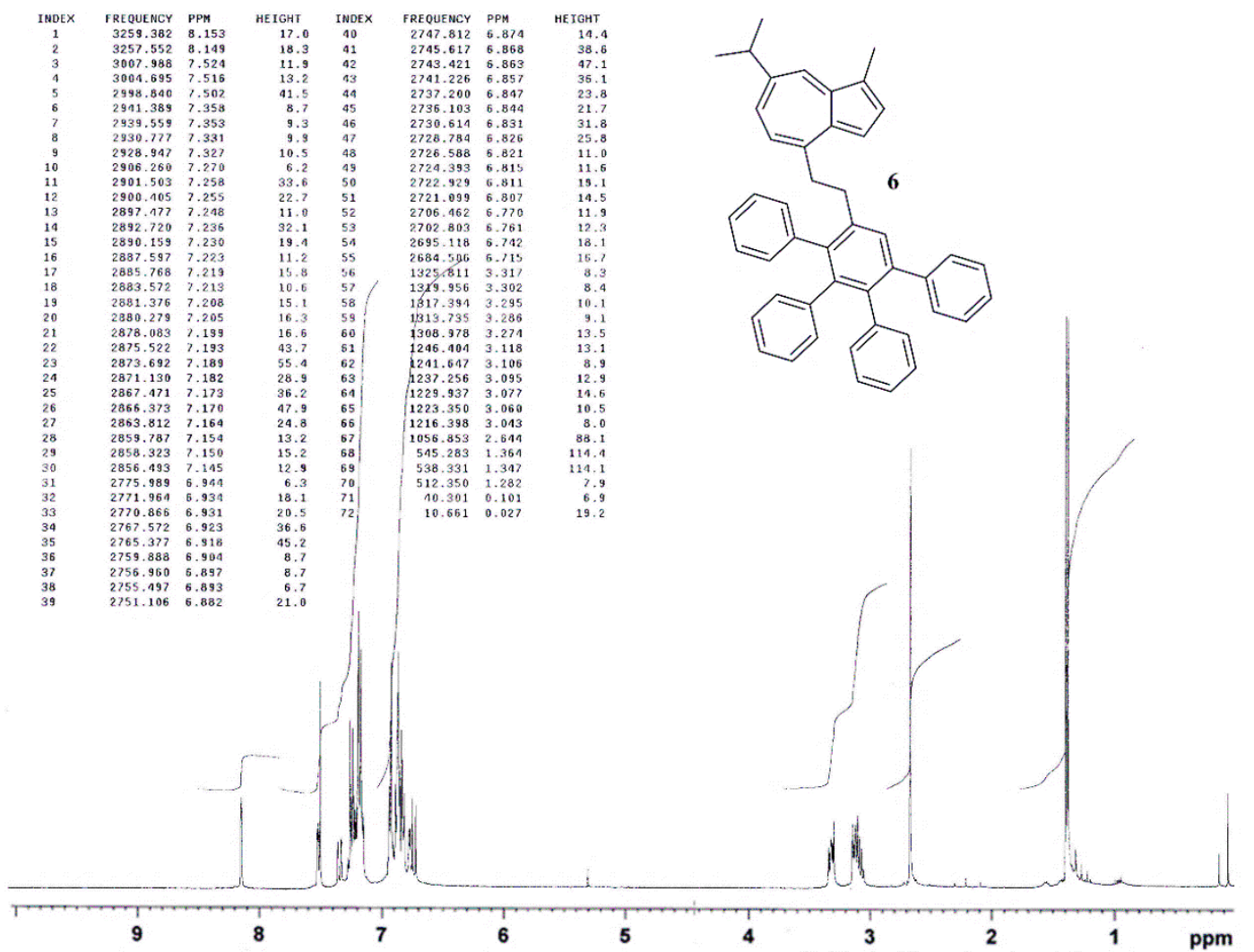

Figure 5. ${ }^{1} \mathrm{H}-\mathrm{NMR}\left(400 \mathrm{MHz}, \mathrm{CDCl}_{3}\right.$ ) spectrum of the compound 6 (Spectra 3). 


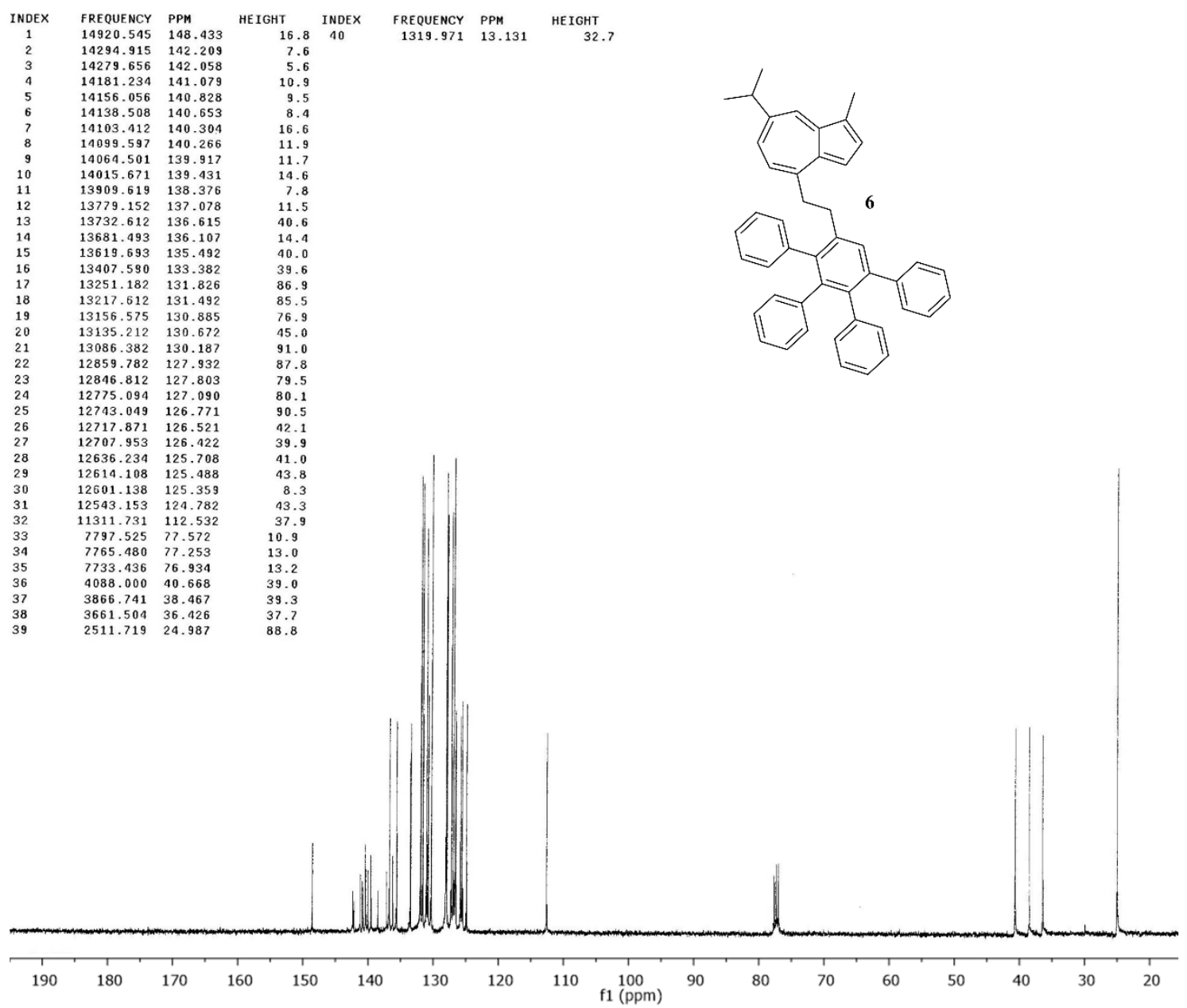

Fig. 6. ${ }^{13} \mathrm{C}-\mathrm{NMR}\left(100 \mathrm{MHz}, \mathrm{CDCl}_{3}\right)$ spectrum of the compound 6 (Spectra 4).

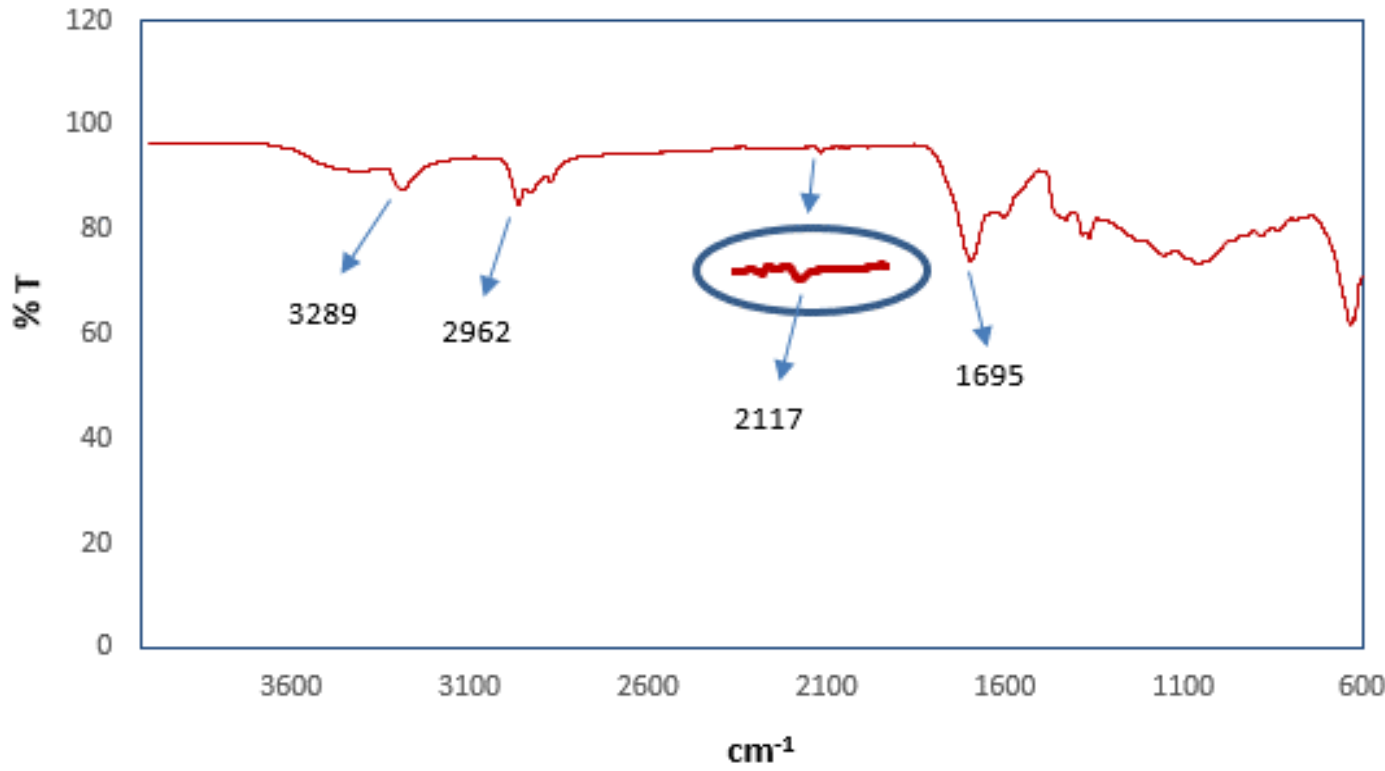

Figure 7. FT-IR spectrum of the compound 4 (Spectra 5). 


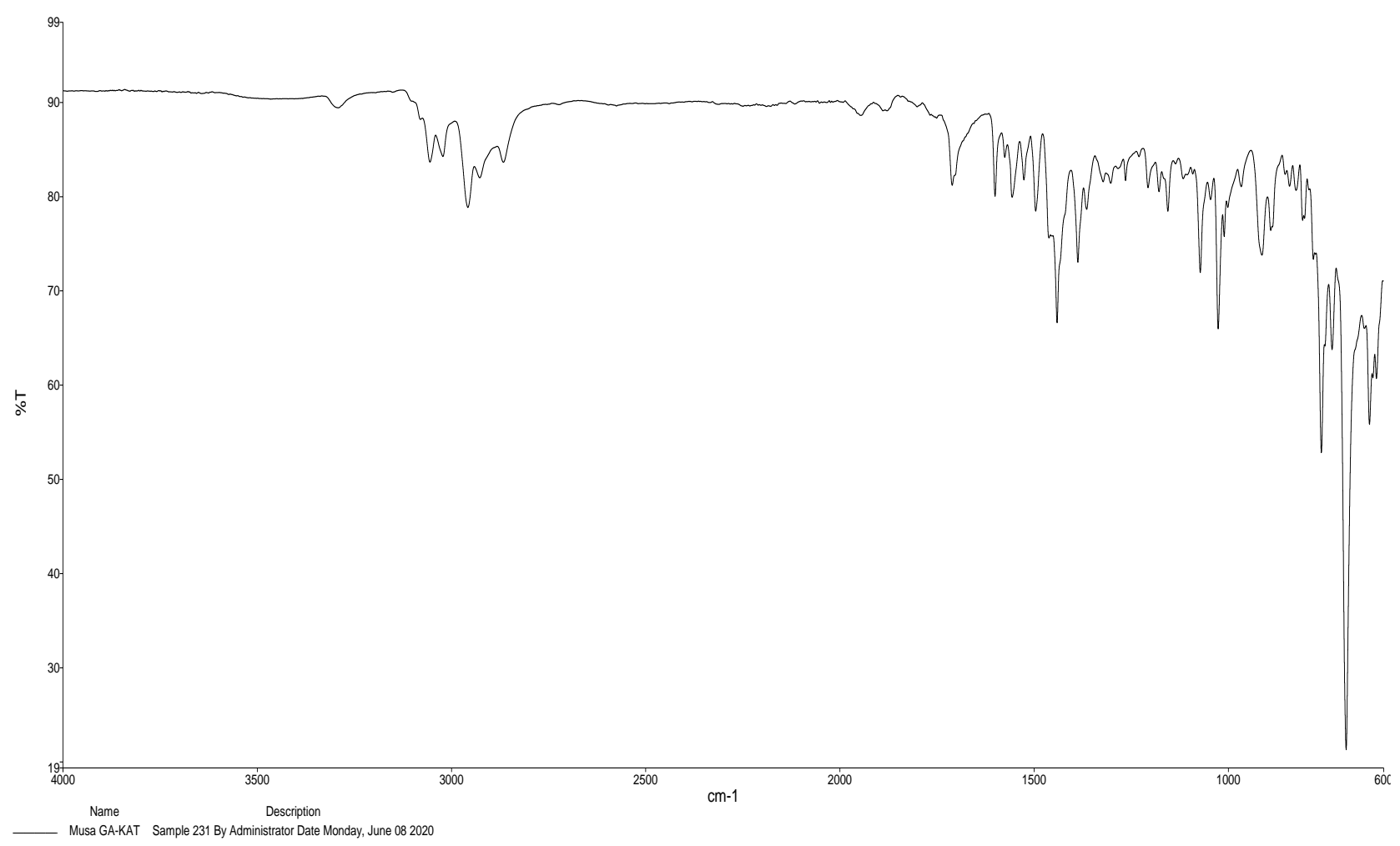

Figure 8. FT-IR spectrum of the compound 6 (Spectra 6) (see the Experimental part for details).

Figure 7 displays FT-IR spectra of the compound 4. The IR spectrum of $\mathbf{4}$ exhibited characteristic absorptions bands for acetylen- $\mathrm{H}$, aromatic $\mathrm{C}-\mathrm{H}$, acetylene functional group, and aromatic $\mathrm{C}=\mathrm{C}$ bonds. The C-H stretch in acetylen-H is observed at $3289 \mathrm{~cm}^{-1}$. The absorption bands at 2962, 2928 and 2871 $\mathrm{cm}^{-1}$ are attributed to aromatic $\mathrm{C}-\mathrm{H}$ bending vibrations of compound 4 . The absorption band at $2117 \mathrm{~cm}^{-}$ ${ }^{1}$ is assigned to stretching vibrations of the acetylene functional group, and those at $1695 \mathrm{~cm}^{-1}$ are due to the aromatic $\mathrm{C}=\mathrm{C}$ groups. Figure 8 displays FT-IR spectra of cycloadduct $\mathbf{6}$. The IR spectrum of $\mathbf{6}$ exhibited characteristic absorptions bands for aromatic $\mathrm{C}-\mathrm{H}$, and aromatic $\mathrm{C}=\mathrm{C}$ bonds. The absorption bands at 3054, 3023, 2958, 2928 and $2866 \mathrm{~cm}^{-1}$ are attributed to aromatic $\mathrm{C}-\mathrm{H}$ bending vibration of the compound 6 . The absorption band at 1710,1600 and $1575 \mathrm{~cm}^{-1}$ are assigned to the stretching vibration of the aromatic $\mathrm{C}=\mathrm{C}$ groups. It was observed that the signal of the propargyl functional group was disappeared in Spectra 6.

\section{UV-vis analysis}

The result of the absorbance measurement for the GA 2, propargyl-GA hybrid derivative 4 and the compound 6 is shown in Figure 9. The UV-vis absorption spectra of the compounds GA 2, propargylGA hybrid derivative 4 and the compound $\mathbf{6}$ in $\mathrm{CH}_{2} \mathrm{Cl}_{2}(5 \mu \mathrm{M})$ are dominated by absorption bands at $\mathbf{2}$; 290, 351, 367, and $396 \mathrm{~nm}, 4$; 284, 354, 356, and $396 \mathrm{~nm}$ and 6; 396, 369, 352 and $340 \mathrm{~nm}$, respectively. These compounds displayed similar band substructures, because of the $\pi$-conjugation is interrupted via methylene or ethylene bridges. 

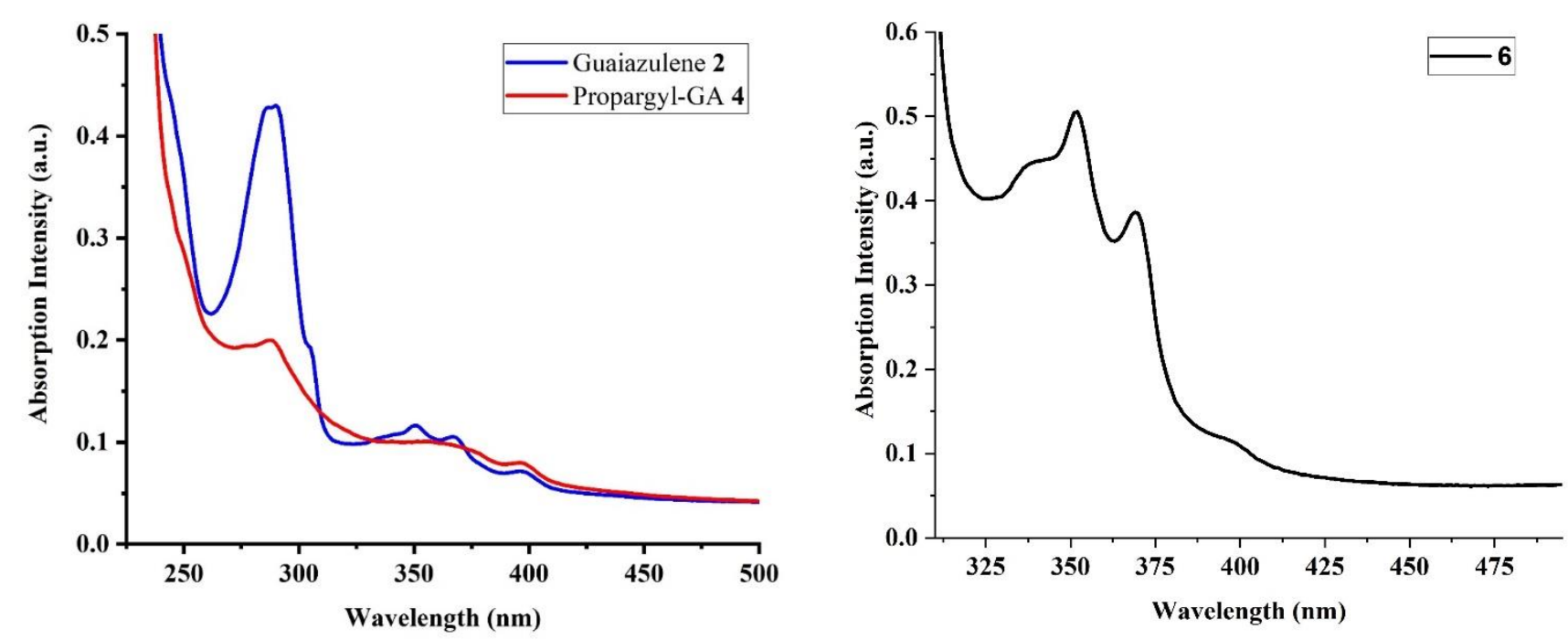

Figure 9. Absorbance spectra of the compounds 2,4 and 6.

\section{CONCLUSION}

A new propargyl-GA hybrid derivatives 4 and $\mathbf{6}$ have been designed, synthesized and characterized. The absorbance properties of these compounds were also investigated. The compound $\mathbf{4}$ was synthesized in excellent yield using the nucleophilic addition reaction. Additionally, Diels-Alder cycloaddition reaction between the propargyl-GA 4 and tetraphenylcyclopentadienone 5 was performed, and then the cycloadduct $\mathbf{6}$ was obtained with excellent yield. We have exhibited that $\mathrm{sp}^{3}$ direct propargylation of GAs is possible when convenient reaction conditions are occupied. The current study potentially also makes inroads into the construction of novel GA for use of other GA derivatives in different applications since the obtained product $\mathbf{4}$ contains the propargyl unit.

\section{ACKNOWLEDGEMENT}

The author is indebted to Atatürk University for its financial support and thanks Professor Arif Daştan for helpful discussions. The author would also like to thank Assistant Professor Yunus Ensari for their technical assistance.

\section{REFERENCES}

Amir E, Amir RJ, Campos LM, Hawker CJ, 2011. Stimuli-responsive azulene-based conjugated oligomers with polyaniline-like properties. Journal of the American Chemical Society, 133(26): 10046-10049.

Asato AE, Peng A, Hossain MZ, Mirzadegan T, Bertram, JS, 1993. Azulenic retinoids: novel nonbenzenoid aromatic retinoids with anticancer activity. Journal of Medicinal Chemistry, 36(21): 3137-3147.

Aumüller IB, Yli-Kauhaluoma J, 2009. Benzo [cd] azulene skeleton: Azulene, heptafulvene, and tropone derivatives. Organic Letters, 11(23): 5363-5365.

Aumüller IB, Yli-Kauhaluoma J, 2011. Synthesis and Tautomerization of Benzo [cd] azulen-3-ones. Organic Letters, 13(7): 1670-1673.

Balduzzi S, Müller-Bunz H, McGlinchey MJ, 2004. A Convenient Synthetic Route to Benz [cd] azulenes: Versatile Ligands with the Potential To Bind Metals in an $\eta 5$, $\eta 6$, or $\eta 7$ Fashion. Chemistry-A European Journal, 10(21): 5398-5405. 
Barman S, Furukawa H, Blacque O, Venkatesan K, Yaghi OM, Berke H, 2010. Azulene based metalorganic frameworks for strong adsorption of $\mathrm{H}_{2}$. Chemical Communications, 46(42): 7981-7983.

Cao T, Li Y, Yang Z, Yuan M, Li Y, Yang H, Yin S, 2016. Synthesis and Biological Evaluation of 3, 8dimethyl-5-isopropylazulene Derivatives as Anti-gastric Ulcer Agent. Chemical Biology \& Drug Design, 88(2): 264-271.

Carret S, Blanc A, Coquerel Y, Berthod M, Greene AE, Deprés JP, 2005. Approach to the blues: a highly flexible route to the azulenes. Angewandte Chemie International Edition, 44(32): 5130-5133.

Chen D, Yu S, van Ofwegen L, Proksch P, Lin W, 2012. Anthogorgienes A-O, new guaiazulene-derived terpenoids from a Chinese gorgonian Anthogorgia species, and their antifouling and antibiotic activities. Journal of Agricultural and Food Chemistry, 60(1): 112-123.

Cowper P, Jin Y, Turton MD, Kociok-Köhn G, Lewis SE, 2016. Azulenesulfonium Salts: accessible, stable, and versatile reagents for cross-coupling. Angewandte Chemie International Edition, 55(7): 2564-2568.

Crombie AL, Kane JL, Shea KM, Danheiser RL, 2004. Ring expansion-annulation strategy for the synthesis of substituted azulenes and oligoazulenes. 2. Synthesis of azulenyl halides, sulfonates, and azulenylmetal compounds and their application in transition-metal-mediated coupling reactions. The Journal of Organic Chemistry, 69(25): 8652-8667.

Ghasimi S, Landfester K, Zhang KA, 2016. Water Compatible Conjugated Microporous Polyazulene Networks as Visible-Light Photocatalysts in Aqueous Medium. ChemCatChem, 8(4): 694-698.

Ghazvini Zadeh EH, Woodward AW, Richardson D, Bondar MV, Belfield KD, 2015. StimuliResponsive Cyclopenta [ef] heptalenes: Synthesis and Optical Properties. European Journal of Organic Chemistry, 2015(10): 2271-2276.

Gordon M, 1952. The Azulenes. Chemical Reviews, 50(1): 127-200.

Imamura M, Nakanishi K, Suzuki T, Ikegai K, Shiraki R, Ogiyama T, Yokota M, 2012. Discovery of ipragliflozin (ASP1941): a novel C-glucoside with benzothiophene structure as a potent and selective sodium glucose co-transporter 2 (SGLT2) inhibitor for the treatment of type 2 diabetes mellitus. Bioorganic \& Medicinal Chemistry, 20(10): 3263-3279.

Kiriazis A, Aumüller IB, Arnaudova R. Brito V, Rüffer T, Lang H, Yli-Kauhaluoma J, 2017. Nucleophilic Substitution of Hydrogen Facilitated by Quinone Methide Moieties in Benzo [cd] azulen-3-ones. Organic Letters, 19(8): 2030-2033.

Kurokawa S, 1983. Synthesis of 2-(4-azulenyl) ethanamine derivatives as a nonbenzenoid analog of biogenic amine. Bulletin of the Chemical Society of Japan, 56(8): 2311-2318.

Narita M, Murafuji T, Yamashita S, Fujinaga M, Hiyama K, Oka Y, Ishiguro K, 2018. Synthesis of 2iodoazulenes by the iododeboronation of azulen-2-ylboronic acid pinacol esters with copper (I) iodide. The Journal of Organic Chemistry, 83(3): 1298-1303.

Park S, Yong WS, Kim S, Lee PH, 2014. Diastereoselective N-Sulfonylaminoalkenylation of Azulenes from Terminal Alkynes and Azides via N-Sulfonyl-1, 2, 3-triazoles. Organic Letters, 16(17): 44684471.

Razus AC, Birzan L, Tecuceanu V, Cristea M, Enache C, 2008. Condensation of alkylazulenes with thiophene-2-carboxaldehyde and the corresponding azomethines. Arkivoc, 11: 210-226.

Seo Y, Rho JR, Geum N, Yoon JB, Shin J, 1996. Isolation of guaianoid pigments from the gorgonian Calicogorgia granulosa. Journal of Natural Products, 59(10): 985-986.

Shoji T, Sugiyama S, Kobayashi Y, Yamazaki A, Ariga Y, Katoh R, Ito S, 2020. Direct synthesis of 2arylazulenes by [8+2] cycloaddition of $2 \mathrm{H}$-cyclohepta [b] furan-2-ones with silyl enol ethers. Chemical Communications. 
Székely A, Péter A, Aradi K, Tolnai GL, Novák Z, 2017. Gold-Catalyzed Direct Alkynylation of Azulenes. Organic Letters, 19(4): 954-957.

Takekuma SI, Yamamoto M, Nakagawa A, Iwata T, Minematsu T, Takekuma H, 2012. Preparation, crystal structure, and spectroscopic, chemical, and electrochemical properties of (2E, 4E)-1, 4-di (3-guaiazulenyl)-1, 3-butadiene compared with those of (E)-1, 2-di (3-guaiazulenyl) ethylene. Tetrahedron, 68(39): 8318-8329.

Tanaka Y, Shigenobu K, 2001. A Review of HNS-32: A Novel Azulene-1-Carboxamidine Derivative with Multiple Cardiovascular Protective Actions. Cardiovascular Drug Reviews, 19(4): 297-312.

Tomiyama T, Yokota M, Wakabayashi S, Kosakai K, Yanagisawa T, 1993. Design, synthesis, and pharmacology of 3-substituted sodium azulene-1-sulfontes and related compounds: nonprostanoid thromboxane A2 receptor antagonists. Journal of Medicinal Chemistry, 36(7): 791-800.

Vlasceanu A, Andersen CL, Parker CR, Hammerich O, Morsing TJ, Jevric M, Nielsen MB, 2016. Multistate Switches: Ruthenium Alkynyl-Dihydroazulene/Vinylheptafulvene Conjugates. Chemistry-A European Journal, 22(22): 7514-7523.

Wang P, Zhu P, Ye C, Asato AE, Liu RS, 1999. Theoretical investigation and molecular design of some azulene derivatives with large hyperpolarizabilities. The Journal of Physical Chemistry A, 103(35): 7076-7082.

Woodward AW, Ghazvini Zadeh EH, Bondar MV, Belfield KD, 2016. Computer aided chemical design: using quantum chemical calculations to predict properties of a series of halochromic guaiazulene derivatives. Royal Society Open Science, 3(11): 160373.

Yanagisawa T, Wakabayashi S, Tomiyama T, Yasunami M, Takase K, 1988. Synthesis and anti-ulcer activities of sodium alkylazulene sulfonates. Chemical and Pharmaceutical Bulletin, 36(2): 641647.

Zadeh EG, Tang S, Woodward AW, Liu T, Bondar MV, Belfield KD, 2015. Chromophoric materials derived from a natural azulene: syntheses, halochromism and one-photon and two-photon microlithography. Journal of Materials Chemistry C, 3(33): 8495-8503.

Zadeh EG, Tang S, Woodward AW, Liu T, Bondar MV, Belfield KD, 2015. Chromophoric materials derived from a natural azulene: syntheses, halochromism and one-photon and two-photon microlithography. Journal of Materials Chemistry C, 3(33): 8495-8503.

Zhang LY, Yang F, Shi WQ, Zhang P, Li Y, Yin SF, 2011. Synthesis and antigastric ulcer activity of novel 5-isoproyl-3, 8-dimethylazulene derivatives. Bioorganic \& Medicinal Chemistry Letters, 21(19): 5722-5725.

Zhao L, Bruneau C, Doucet H, 2013. A straightforward access to guaiazulene derivatives using palladium-catalysed sp 2 or sp $3 \mathrm{C}-\mathrm{H}$ bond functionalisation. Chemical Communications, 49(49): 5598-5600. 